\title{
A Clinical Phenotyping Algorithm to Identify Cases of Chronic Obstructive Pulmonary Disease in Electronic Health Records
}

Victoria L. Martucci ${ }^{1,2}$, Nancy Liü ${ }^{2}$, V. Eric Kerchberger ${ }^{3,4}$, Travis J. Osterman ${ }^{4,5}$, Eric Torstenson ${ }^{1}$, Bradley Richmond ${ }^{3,6}$, Melinda C. Aldrich ${ }^{1,2,4,7}$

1) Vanderbilt Genetics Institute, Vanderbilt University School of Medicine, Nashville, TN

2) Department of Thoracic Surgery, Vanderbilt University Medical Center, Nashville, TN

3) Department of Medicine, Division of Allergy, Pulmonary, and Critical Care Medicine, Vanderbilt University Medical Center, Nashville, TN

4) Department of Biomedical Informatics, Vanderbilt University Medical Center, Nashville, TN

5) Department of Medicine, Division of Hematology and Oncology, Vanderbilt University Medical Center, Nashville, TN

6) Department of Veteran Affairs Medical Center, Nashville, TN

7) Department of Medicine, Division of Epidemiology, Vanderbilt University Medical Center, Nashville, TN

Formatted for Annals of the American Thoracic Society

Word Count: 3,497 [max 3,500]

Abstract Word Count: 241 [max 350]

Tables and Figures: 6

Supplementary Tables and Figures: 8 


\section{Abstract}

Rationale. Chronic obstructive pulmonary disease (COPD) is a leading cause of mortality in the United States. Electronic health records provide large-scale healthcare data for clinical research, but have been underutilized in COPD research due to challenges identifying these individuals, especially in the absence of pulmonary function testing data.

Objectives. To develop an algorithm to electronically phenotype individuals with COPD at a large tertiary care center.

Methods. We identified individuals over 45 years of age at last clinic visit within Vanderbilt University Medical Center electronic health records. We tested phenotyping algorithms using combinations of both structured and unstructured text and examined the clinical characteristics of the resulting case sets.

Measurement and Main Results. A simple algorithm consisting of 3 International Classification of Disease codes for COPD achieved a sensitivity of $97.6 \%$, a specificity of $76.0 \%$, a positive predictive value of $57.1 \%$, and a negative predictive value of $99.0 \%$. A more complex algorithm consisting of both billing codes and a mention of oxygen on the problem list that achieved a positive predictive value of $86.5 \%$. However, the association of known risk factors with chronic obstructive pulmonary disease was consistent in both algorithm sets, suggesting a simple codeonly algorithm may suffice for many research applications.

Conclusions. Simple code-only phenotyping algorithms for chronic obstructive pulmonary disease can identify case populations with epidemiologic and genetic profiles consistent with published literature. Implementation of this phenotyping algorithm will expand opportunities for clinical research and pragmatic trials for COPD.

Key words: chronic obstructive pulmonary disease, phenotyping, electronic health records 


\section{Introduction}

Chronic obstructive pulmonary disease (COPD) is a leading cause of death globally.(1) Within the United States, approximately $6.3 \%$ of adults live with COPD, contributing to $\$ 32.1$ billion in health care costs annually. $(2,3)$ Individuals with COPD have high rates of hospitalization, health care utilization, and all-cause mortality, as well as increased mortality from comorbid conditions such as cardiovascular disease, kidney disease, and lung cancer.(47) COPD is characterized by small airway narrowing and obliteration and emphysematous lung destruction, which together lead to progressive obstruction in expiratory airflow.(8) The clinical gold standard for a COPD diagnosis is demonstration of irreversible airflow limitation assessed via pulmonary function testing (PFT). $(8,9)$ However, routine screening for COPD is not recommended, particularly among asymptomatic patients,(10) and PFTs are underutilized in clinical settings. $(11,12)$ Discovering a reliable means to identify COPD cases in electronic health records (EHRs) in the absence of PFTs could greatly facilitate advances in COPD clinical research. To date, most research studies have relied on well-curated cohorts to further our understanding of COPD risks and outcomes.(13-17) These observational cohorts are costly and time-consuming to develop, hampering rapid advances in research. EHR provide a valuable tool to expand and potentially accelerate clinical research of COPD.(18) EHR also allow unique opportunities for pragmatic clinical trials, with an unprecedented depth of information that can be used to rapidly and cost-effectively identify trial participants, study medical interventions and outcomes in real-world settings, and prioritize interventions for testing in randomized controlled trials.(19-22) The development of a robust and portable algorithm to identify COPD cases in the absence of PFTs is needed to enable genetics research leveraging biobanks and pragmatic clinical trials for COPD.

Relatively few attempts have been made to develop such an algorithm for COPD. Himes et al. developed an algorithm to predict COPD in asthma patients, but the generalizability of this algorithm to COPD not associated with asthma is unclear.(23) Several algorithms to identify 
COPD within primary care and administrative claims databases have been developed.(24-31) The performance of these algorithms varies greatly, with positive predictive values (PPV) ranging from $36.7 \%$ to $94 \% .(24,26,27,29-31)$ However, algorithms with higher PPVs had lower sensitivities, meaning many cases of COPD were missed. These algorithms were predominantly developed in primary care populations in Canada and Europe. Therefore, the generalizability to hospital-based populations in the United States is unclear. To our knowledge, the only phenotyping algorithm for COPD in United States hospital-based clinical populations was used in a recent genetic association study by Wain et al.,(32) yet the algorithm performance was not reported.

Vanderbilt University Medical Center (VUMC) has a well-characterized EHR of clinical data captured through routine care. We used de-identified data from the VUMC clinical population to develop and evaluate EHR-based COPD phenotyping algorithms. We also characterized the COPD cases with regards to established risk factors, candidate genetic variants, and comorbidities.

\section{Methods}

\section{Synthetic Derivative}

We used clinical data from the Vanderbilt Synthetic Derivative (SD), a de-identified version of the VUMC EHR, containing data on over 2.1 million adult patients and over 1 billion unique observations dating back to the 1980s.(33) Details regarding SD development have been previously published.(33) Extractable PFT data have been available since 2011. The Vanderbilt University Institutional Review Board approved this study.

Demographic data, International Classification of Disease (ICD) 9 and ICD-10 codes, and PFTs were obtained from structured fields in the SD. Quality control was implemented to remove individuals with record lengths (defined as the number of days from the first clinical encounter and the most recent clinical encounter) longer than their age. Natural language 
processing mined additional text for medications for treatment of COPD; radiology report mentions of emphysema (excluding subcutaneous emphysema); and mentions of COPD, emphysema, chronic bronchitis, cough, shortness of breath, or oxygen use on the problem list (Table S1). We implemented negation for radiology reports using PyConTextNLP, a Python algorithm that considers the context around keywords, and a previously curated list of negation terms. $(34,35)$ Smoking information was collected from unstructured clinical notes. Due to current lack of granularity in patient smoking behaviors in the clinical record,(36) we simplified smoking information to a dichotomous variable of ever versus never smoker.

\section{Algorithm Development and Validation}

The study population consisted of adults over 45 years of age at last clinic visit who visited VUMC prior to March 8, 2019. We identified individuals with available PFT data and randomly sampled 200 patients for our development set (Figure 1). PFTs were used as the gold standard, with cases defined as individuals with a forced expiratory volume in one second $\left(F V_{1}\right)$ to forced vital capacity $(F V C)<0.7$ after bronchodilator administration. We developed a series of algorithms combining COPD ICD codes and additional clinical data (Table S1). To internally validate our algorithm performance, we tested them in an independent random sample of 200 records. Stratified random sampling was used to select 100 individuals with two or more COPD ICD-9 or ICD-10 codes and 100 individuals with fewer than two COPD ICD codes. Gold standard chart review was performed by two independent reviewers (VLM and VEK) with clinical training. Discrepancies were adjudicated by a pulmonary physician (BR). Kappa statistics were calculated to determine agreement between reviewers.(37) A second internal validation was performed using all individuals with available PFTs, excluding the 200 records used in the development set $(\mathrm{N}=13,858)$. 
We applied the algorithms to the entire SD population over 45 years of age at last visit to calculate the number of cases, controls, indeterminates, and excluded individuals. To ensure cases and controls had similar opportunity for eligibility, we selected a study population with a minimum record length of 180 days (6 months). We then examined the relationship between known risk factors (age, sex, and smoking history) and algorithm-defined COPD case-control status using logistic regression models.

To demonstrate potential applications of our algorithms, we explored comorbidity data within our algorithm-defined cases using phecodes. Phecodes are aggregated ICD-9 codes that condense similar disease entities into one code, reducing the number of phenotypes from over 14,000 separate ICD-9 codes to 1,645 phecode groups, and have been utilized in multiple EHR and genetic studies.(38-44) We also conducted genetic analyses using COPD-associated single nucleotide polymorphisms (SNPs) previously identified by Wain et al.(32) Genotyping data was obtained from BioVU, a Vanderbilt biobank with de-identified genotyping and clinical data.(33) Data from the Illumina MEGA-Ex array were subjected to quality control to remove individuals and SNPs with $<98 \%$ call rates, SNPs with minor allele frequency $<1 \%$, and SNPs not in Hardy-Weinberg equilibrium ( $p$-value threshold of $1 \times 10^{-6}$ ). After quality control, genotyping data were available on 41,660 physician-reported white adults over 45 years of age. Principal component (PC) analysis was performed using EIGENSTRAT on a set of SNPs pruned for linkage disequilibrium.(45) A log-additive model was assumed for individual SNPs and logistic regression analyses were performed to examine the association between SNPs and COPD, adjusting for age at last clinic visit, age ${ }^{2}$, sex, height, and the first 10 PCs for ancestry using Plink v1.9.(46)

\section{Results}

Study Population 
As of March 8, 2019, we identified 1,008,661 individuals age 45 or older at last clinic visit. Quality control removed 109 individuals, leaving 1,008,552 individuals. For our initial algorithm development, we randomly sampled 200 charts with PFT data. The median age at last clinic visit was 65 years, with a median record length of 8.6 years. The development set had roughly equal percentages of males (49.0\%) and females (51.0\%) and was largely of observerreported European descent (82.0\%). The majority were smokers (56.5\%) (Table 1). Our first internal validation set consisted of 200 records that underwent chart review. The population characteristics of the chart review validation set were similar to those of the development set, although there were fewer smokers in this set (40.5\%) (Table 1). The kappa statistic between clinical reviewers was 0.75 , and 18 discrepancies were adjudicated by a third reviewer. Our second internal validation set consisted of all individuals with available PFTs, excluding records used for development. The PFT validation set had similar characteristics to the chart review validation set, although individuals in this set had a longer record length (median 8.8 years) and higher smoking percentage $(55.0 \%)$ than the chart review set or the overall SD (Table 1$)$.

\section{Algorithm development and performance in validation sets}

We tested algorithms using different combinations of clinical text and COPD ICD codes in our development set (Table S1). Based on algorithm performance and complexity, we proceeded with two case algorithms and one control algorithm in the validation phase. The case and control definitions were as follows:

1. 3+ codes: A rule-based classifier that required three or more ICD codes for COPD (Figure 2)

2. Code + regex: A rule-based classifier that required at least 10 or more ICD codes for COPD OR presence of three to nine ICD codes for COPD AND a text mention of oxygen use on the problem list (Figure S1). 
3. Controls: A rule-based classifier requiring no ICD codes for COPD AND no ICD codes for asthma $O R$ idiopathic pulmonary fibrosis $O R$ sarcoidosis (Figure 2).

The $3+$ code algorithm had a sensitivity of $97.6 \%$, specificity of $76.0 \%$, PPV of $57.1 \%$, NPV of 99.0\%, and F-measure of 0.72 in the chart review validation set (Table 2). All calculated performance metrics were lower in the PFT validation set (Table 2). The code + regex algorithm had the highest specificity (95.0\%), PPV (86.5\%), and F-measure (0.91) in the chart review validation set (Table 2). This algorithm also had the best performance in terms of specificity (79.1\%), PPV (39.8\%), and F-measure (0.53) in the PFT validation set (Table 2).

\section{Application of algorithms to EHR dataset}

To demonstrate the utility of our algorithms within a large EHR database, we applied them to the entire adult SD population over 45 years of age at last visit with record lengths longer than 6 months (180 days, $\mathrm{N}=623,986$ ). The $3+$ code-only algorithm identified 28,520 COPD cases ( $5.0 \%$ of adults meeting inclusion criteria) and 544,056 controls $(95.0 \%)$ (Table S2). There were 23,091 individuals labeled as indeterminates due to too few COPD ICD codes and 28,319 individuals excluded from the control set due to the presence of asthma, sarcoidosis, or idiopathic pulmonary fibrosis codes. Using the code + regex algorithm decreased the case number to 12,622 (2.3\%) (Table S2). Exclusively using PFT-defined COPD identified 2,015 individuals (14.3\%) who met the GOLD definition for COPD (post-bronchodilator $\left.\mathrm{FEV}_{1} / \mathrm{FVC}<0.7\right)($ Table S2).(8)

We compared the case sets identified by the $3+$ code algorithm, the code + regex algorithm, and the gold standard PFT definition. The age, sex, and race distributions were similar in all three groups (Table S3). PFT-defined cases had a higher prevalence of ever smokers $(1,464,78.2 \%)$ compared to $3+$ ICD code COPD cases $(15,645,54.9 \%)$ and code + regex COPD cases $(7,548,59.8 \%)$. The median record length was longer in PFT-defined cases (10.3 years) than in $3+$ ICD code cases (7.3 years) and code + regex cases (8.3 years). We 
also looked at the overlap in sample size between cases identified by the $3+$ code algorithm and those identified by PFTs. There were 1,265 cases present in both sets (Figure 3). The remaining 607 PFT cases (32.4\% of all PFT cases with record lengths longer than 6 months) were not identified by our algorithm, and 27,255 algorithm cases were not identified by PFTs. We compared $\mathrm{FEV}_{1}$ percent predicted and $\mathrm{FEV} / \mathrm{FVC}$ measurements in PFT cases with 3+ ICD codes and PFT cases with fewer than three ICD codes. In both pre- and post-bronchodilator measures, the median $\mathrm{FEV}_{1}$ percent predicted and $\mathrm{FEV}_{1} / \mathrm{FVC}$ were lower among PFT cases with 3+ COPD ICD codes than those with fewer codes (Figure S2).

\section{Confirmation of known clinical risk factors in algorithm COPD cases}

To further inform our algorithm choice, we compared the odds ratios (OR) examining the associations between COPD status and known clinical risk factors in each algorithm-defined population. Using the 3+ code algorithm, the OR for COPD associated with age at last clinic visit was 1.04 , with male sex was 1.40 , and with ever smoking was 9.22 . The code + regex algorithm and PFT-based definition all showed similar OR for age, sex, and smoking (Table S4). Since the associations did not differ meaningfully between the different algorithms tested, we chose to focus on the $3+$ code algorithm due to its simplicity and larger case sample size.

\section{Clinical and genetic analyses using a phenotyping algorithm}

To highlight the potential of our algorithm for clinical research, we explored the case population identified by our $3+$ code algorithm. Cases identified by the $3+$ code algorithm were older (median age 69) and had longer record lengths (median 7.3 years) than controls (median age 62, median record length 6.2 years) (Table 3$)$. The percentage of males $(53.2 \%)$, whites (86.9\%), and ever-smokers (54.9\%) among COPD cases were higher than among controls (Table 3). 
In addition to basic demographic data, we found that cases had a higher median number of respiratory medications per individual than controls (16) (Table 3). We also compared the frequency of phecodes across the two groups.(38-44) In COPD cases, the most frequent phecodes were chronic airway obstruction (100\%), hypertension $(77.1 \%)$, other symptoms of respiratory system (75.4\%), essential hypertension (75.4\%), and tobacco use disorder (63.0\%). In controls, the most frequent phecodes were hypertension (37.0\%), essential hypertension $(36.2 \%)$, disorders of lipoid metabolism (26.1\%), hyperlipidemia (26.0\%), and other symptoms of respiratory system (24.1\%) (Table 3). The most frequent phecodes in the code + regex algorithm cases and PFT cases were similar, with the exception of tobacco use disorder, which was only seen in the five most frequent phecodes for $3+$ code cases (Table S3). However, the frequency of the tobacco use disorder phecode was similar in the code + regex cases $(68.0 \%)$ and in the PFT-defined cases (60.5\%) (data not shown). We also describe characteristics of the PFT-defined cases and controls (Table S5).

We performed genetic analyses using single nucleotide polymorphisms from a recent genome-wide association study of COPD by Wain et al.(32) Of the 95 SNPs significantly associated with lung function, 41 were present in our Illumina MEGA array genotyping data. For all but seven of the 41 SNPs present, the confidence intervals from our genetic associations and the confidence intervals from the Wain study overlapped (Figure S3).

\section{Discussion and Conclusions}

Our goal was to develop a phenotyping algorithm for COPD for use in EHR that did not rely on PFTs. While previous studies have also developed phenotyping algorithms for COPD, the population we used in this study is unique. Six of the previously published studies were done in primary care populations in Canada or the United Kingdom.(24, 25, 27, 29-31) Another prior study relied exclusively on insurance claims data.(28) To our knowledge, the only prior study that used an inpatient-based population to electronically phenotype COPD was done by 
Lacasse et al. However, their primary goal was to determine whether hospital discharge diagnoses of COPD was a valid metric for identifying COPD cases, so they identified cases only and no controls.(26) As a tertiary care center, the VUMC patient population typically represents more complex and severe cases of disease. Furthermore, the Southeast United States, where VUMC is located, has a higher smoking prevalence and COPD prevalence than the national average. $(1,47)$ Implementation of a COPD phenotyping algorithm in clinical centers where COPD prevalence is among the nation's highest represents an opportunity to utilize our electronic health systems to address a leading cause of morbidity and mortality.

We also sought to develop an algorithm that was easy to implement so it could be deployed across different health care systems to enable clinical research and pragmatic clinical trials. In addition to calculating clinical validity metrics, we considered demographic and clinical characteristics of the resulting COPD case and control groups when selecting our algorithm. While performance metrics are valuable, EHR present unique challenges that necessitate a more nuanced approach. Data missingness is a common problem in EHR-based research.(4856) This is particularly true in a tertiary referral center such as VUMC, where patients often receive routine clinical care at other institutions. We found that adding more stringent criteria for cases did improve our PPV, but did not greatly impact the clinical characteristics of the case sets identified (Table S4). The strength of association between COPD and established risk factors such as age, sex, and smoking did not differ between our high PPV code + regex algorithm cases and the less stringent $3+$ code algorithm cases. The genetic profile of the cases identified by our 3+ code algorithm is also consistent with previous research (Figure S3).(32) By requiring more clinical data, our code + regex algorithm biased our case sample to individuals with more severe disease, since sicker patients typically have denser documentation and more complete data in EHR.(56)

We recognize that in some research settings, a more stringent case definition and higher PPV may be more appropriate. In such settings, our code + regex algorithm may be a better 
choice, since it can achieve a PPV of up to $86.5 \%$ (Table 2). For facilities that lack the phenotyping resources to extract more complex clinical data such as oxygen use, we also tested a case definition requiring 5+ ICD codes only. This algorithm had a higher PPV (70.6\%) in our chart review validation set than our $3+$ code-only algorithm (57.1\%). The specificity of the $5+$ code-only algorithm was also higher (86.4\%) compared to the 3+ code-only algorithm (76.0\%). The NPV remained the same, and only the sensitivity decreased slightly $(97.3 \%$ in the $5+$ code-only algorithm vs. $97.6 \%$ in the $3+$ code-only algorithm) (data not shown). The same pattern in performance changes was seen in the PFT validation set (data not shown). This relatively simple change to our $3+$ code-only algorithm can be used in settings where more advanced phenotyping is not possible.

For all our algorithms, we found that the performance was higher in the chart review validation set than in the PFT set. This is likely due to the enrichment of respiratory disease in the PFT set. PFTs are not performed for routine screening, so individuals referred for PFT typically have some respiratory compromise.(57) Many of the variables we included in our algorithms are present in individuals with other respiratory conditions. A few of the individuals classified as cases by our algorithm had PFTs that were not consistent with the GOLD definition of COPD.(8) This may be due to an absence of temporal data in our study. We did not require individuals to have received PFTs and ICD codes for COPD in any particular order or time frame. Therefore, individuals labeled as controls in the PFT set may have received PFTs for early respiratory decline that did not meet the official definition for COPD at the time. It is possible that these individuals experienced continued lung function decline that eventually progressed to COPD, but never received follow-up PFTs at VUMC. The overlap between COPD and other respiratory conditions and the high prevalence of respiratory disease in our PFT set likely explain the reduced algorithm performance in the PFT set.

This study has several limitations. As previously mentioned, the use of EHR in biomedical research has inherent challenges due to inconsistent documentation, missing data, 
and inaccuracies.(48-56) Tertiary care EHR data often have sicker patients with denser clinical documentation and more complete data than other hospital settings.(56) COPD cases identified by our algorithm have more severe COPD based on $\mathrm{FEV}_{1}$ and $\mathrm{FEV}_{1} / \mathrm{FVC}$ measurements (Figure S2). Our algorithm relied heavily on ICD code information, which can be inaccurate, particularly for secondary research use. $(58,59)$ However, our analyses of known COPD risk factors and previous genetic associations suggest that the population identified by our algorithm has similar epidemiologic and genetic characteristics to previously studied COPD populations.(60) Furthermore, we present a second algorithm, the code + regex algorithm, that includes oxygen use on the problem list in addition to ICD codes. This approach has been previously demonstrated to improve phenotyping accuracy.(58) Another limitation is the predominance of individuals of European descent in our study population. This may limit generalizability to other populations. Replication in other EHR systems with greater diversity is needed to address this.

A key advantage to our case population is the wealth of clinical information contained within the EHR, which can be leveraged for clinical research. The addition of a linked DNA repository provides unique opportunities for COPD genetics research. Application of our phenotyping algorithm allowed us to identify a large population with COPD for research, without the additional time and cost investments typically required to build epidemiologic cohorts.

Overall, our study demonstrates that phenotyping algorithms for COPD can be successfully implemented in EHR in a tertiary hospital setting. We present several algorithms with different clinical validity metrics, as we recognize the best algorithm may vary depending on the research question. Use of COPD phenotyping algorithms can quickly and easily identify large cohorts for clinical research studies within EHR, which will facilitate accelerated scientific discoveries and precision medicine opportunities for this devastating disease.

\section{Acknowledgements}


bioRxiv preprint doi: https://doi.org/101101/716779; this version posted July 28, 2019. The copyright holder for this preprint (which was not certified by peer review) is the author/funder, who has granted bioRxiv a license to display the preprint in perpetuity. It is made available under aCC-BY-NC-ND 4.0 International license.

This work was supported in part by NIGMS (T32GM007347 and T32GM080178), NHLBI (F30HL140756) and the Vanderbilt CTSA grant UL1TR002243 from NCATS/NIH. 


\section{References}

1. Centers for Disease Control and Prevention. Chronic Obstructive Pulmonary Disease Among Adults — United States, 2011. MMWR 2012;61:938-943.

2. Croft JB. Urban-Rural County and State Differences in Chronic Obstructive Pulmonary Disease — United States, 2015. MMWR Morb Mortal Wkly Rep 2018;67:.

3. Ford ES, Murphy LB, Khavjou O, Giles WH, Holt JB, Croft JB. Total and State-Specific Medical and Absenteeism Costs of COPD Among Adults Aged 18 Years in the United States for 2010 and Projections Through 2020. Chest 2015;147:31-45.

4. Yoshida Y, Kage H, Murakawa T, Sato Y, Ota S, Fukayama M, Nakajima J. Worse Prognosis for Stage IA Lung Cancer Patients with Smoking History and More Severe Chronic Obstructive Pulmonary Disease. Annals of Thoracic and Cardiovascular Surgery 2015;21:194-200.

5. Navaneethan SD, Schold JD, Huang H, Nakhoul G, Jolly SE, Arrigain S, Dweik RA, Jr JVN. Mortality Outcomes of Patients with Chronic Kidney Disease and Chronic Obstructive Pulmonary Disease. AJN2016;43:39-46.

6. Rothnie KJ, Smeeth L, Herrett E, Pearce N, Hemingway H, Wedzicha J, Timmis A, Quint JK. Closing the mortality gap after a myocardial infarction in people with and without chronic obstructive pulmonary disease. Heart 2015;101:1103-1110.

7. Yoshihisa A, Takiguchi M, Shimizu T, Nakamura Y, Yamauchi H, Iwaya S, Owada T, Miyata M, Abe S, Sato T, Suzuki S, Oikawa M, Kobayashi A, Yamaki T, Sugimoto K, Kunii H, Nakazato K, Suzuki H, Saitoh S, Takeishi Y. Cardiovascular function and prognosis of patients with heart failure coexistent with chronic obstructive pulmonary disease. Journal of Cardiology 2014;64:256-264.

8. GOLD 2017 Global Strategy for the Diagnosis, Management and Prevention of COPD. Global Initiative for Chronic Obstructive Lung Disease - GOLD at <http://goldcopd.org/>. 
9. Viegi G, Pistelli F, Sherrill DL, Maio S, Baldacci S, Carrozzi L. Definition, epidemiology and natural history of COPD. European Respiratory Journal 2007;30:993-1013.

10. Siu AL, Bibbins-Domingo K, Grossman DC, Davidson KW, Epling JW, García FAR, Gillman M, Kemper AR, Krist AH, Kurth AE, Landefeld CS, Mangione CM, Harper DM, Phillips WR, Phipps MG, Pignone MP. Screening for Chronic Obstructive Pulmonary Disease: US Preventive Services Task Force Recommendation Statement. JAMA 2016;315:1372-1377.

11. Yu WC, Fu SN, Tai EL, Yeung YC, Kwong KC, Chang Y, Tam CM, Yiu YK. Spirometry is underused in the diagnosis and monitoring of patients with chronic obstructive pulmonary disease (COPD). International Journal of Chronic Obstructive Pulmonary Disease 2013;8:389-395.

12. Joo MJ, Sharp LK, Au DH, Lee TA, Fitzgibbon ML. Use of Spirometry in the Diagnosis of COPD: A Qualitative Study in Primary Care. COPD 2013;10:444-449.

13. Regan EA, Hokanson JE, Murphy JR, Make B, Lynch DA, Beaty TH, Curran-Everett D, Silverman EK, Crapo JD. Genetic Epidemiology of COPD (COPDGene) Study Design. COPD: Journal of Chronic Obstructive Pulmonary Disease 2011;7:32-43.

14. Bourbeau J, Tan WC, Benedetti A, Aaron SD, Chapman KR, Coxson HO, Cowie R, Fitzgerald M, Goldstein R, Hernandez P, Leipsic J, Maltais F, Marciniuk D, O'Donnell D, Sin DD, Cancold Study Group. Canadian Cohort Obstructive Lung Disease (CanCOLD): Fulfilling the Need for Longitudinal Observational Studies in COPD. COPD: Journal of Chronic Obstructive Pulmonary Disease 2014;11:125-132.

15. Vestbo J, Anderson W, Coxson HO, Crim C, Dawber F, Edwards L, Hagan G, Knobil K, Lomas DA, MacNee W, Silverman EK, Tal-Singer R, ECLIPSE investigators. Evaluation of COPD Longitudinally to Identify Predictive Surrogate End-points (ECLIPSE). European Respiratory Journal 2008;31:869-873. 
16. Eagan TML, Ueland T, Wagner PD, Hardie JA, Mollnes TE, Damås JK, Aukrust P, Bakke PS. Systemic inflammatory markers in COPD: results from the Bergen COPD Cohort Study. European Respiratory Journal 2010;35:540-548.

17. Watz H, Waschki B, Meyer T, Magnussen H. Physical activity in patients with COPD. European Respiratory Journal 2009;33:262-272.

18. Centers for Disease Control and Prevention. Public Health Strategic Framework for COPD Prevention. at <https://www.cdc.gov/copd/resources.htm>.

19. Schwartz D, Lellouch J. Explanatory and Pragmatic Attitudes in Therapeutical Trials. Journal of Clinical Epidemiology 2009;5:499-505.

20. Ford I, Norrie J. Pragmatic Trials. New England Journal of Medicine 2016;375:454-463.

21. Staa T-P van, Goldacre B, Gulliford M, Cassell J, Pirmohamed M, Taweel A, Delaney B, Smeeth L. Pragmatic randomised trials using routine electronic health records: putting them to the test. BMJ 2012;344:e55.

22. Richesson RL, Hammond WE, Nahm M, Wixted D, Simon GE, Robinson JG, Bauck AE, Cifelli D, Smerek MM, Dickerson J, Laws RL, Madigan RA, Rusincovitch SA, Kluchar C, Califf RM. Electronic health records based phenotyping in next-generation clinical trials: a perspective from the NIH Health Care Systems Collaboratory. J Am Med Inform Assoc 2013;20:e226-e231.

23. Himes BE, Dai Y, Kohane IS, Weiss ST, Ramoni MF. Prediction of Chronic Obstructive Pulmonary Disease (COPD) in Asthma Patients Using Electronic Medical Records. J Am Med Inform Assoc 2009;16:371-379.

24. Williamson T, Green ME, Birtwhistle R, Khan S, Garies S, Wong ST, Natarajan N, Manca D, Drummond N. Validating the 8 CPCSSN Case Definitions for Chronic Disease Surveillance in a Primary Care Database of Electronic Health Records. Ann Fam Med 2014;12:367-372. 
25. Soriano JB, Maier WC, Visick G, Pride NB. Validation of general practitioner-diagnosed COPD in the UK General Practice Research Database. Eur J Epidemiol 2001;17:10751080.

26. Lacasse Y, Daigle J-M, Martin S, Maltais F. Validity of Chronic Obstructive Pulmonary Disease Diagnoses in a Large Administrative Database. Canadian Respiratory Journal 2012;19:e5-9.

27. Smidth M, Sokolowski I, Kærsvang L, Vedsted P. Developing an algorithm to identify people with Chronic Obstructive Pulmonary Disease (COPD) using administrative data. $B M C$ Medical Informatics and Decision Making 2012;12:38.

28. Mapel DW, Dutro MP, Marton JP, Woodruff K, Make B. Identifying and characterizing COPD patients in US managed care. A retrospective, cross-sectional analysis of administrative claims data. BMC Health Services Research 2011;11:43.

29. Coleman N, Halas G, Peeler W, Casaclang N, Williamson T, Katz A. From patient care to research: a validation study examining the factors contributing to data quality in a primary care electronic medical record database. BMC Family Practice 2015;16:11.

30. Quint JK, Müllerova H, DiSantostefano RL, Forbes H, Eaton S, Hurst JR, Davis K, Smeeth L. Validation of chronic obstructive pulmonary disease recording in the Clinical Practice Research Datalink (CPRD-GOLD). BMJ Open 2014;4:e005540.

31. Lee TM, Tu K, Wing LL, Gershon AS. Identifying individuals with physician-diagnosed chronic obstructive pulmonary disease in primary care electronic medical records: a retrospective chart abstraction study. NPJ Prim Care Respir Med 2017;27:34.

32. Wain LV, Shrine N, Artigas MS, Erzurumluoglu AM, Noyvert B, Bossini-Castillo L, Obeidat M, Henry AP, Portelli MA, Hall RJ, Billington CK, Rimington TL, Fenech AG, John C, Blake T, Jackson VE, Allen RJ, Prins BP, Understanding Society Scientific Group, Campbell A, Porteous DJ, Jarvelin M-R, Wielscher M, James AL, Hui J, Wareham NJ, Zhao JH, Wilson JF, Joshi PK, et al. Genome-wide association analyses for lung function and chronic 
obstructive pulmonary disease identify new loci and potential druggable targets. Nat Genet 2017;49:416-425.

33. Roden D, Pulley J, Basford M, Bernard G, Clayton E, Balser J, Masys D. Development of a Large-Scale De-Identified DNA Biobank to Enable Personalized Medicine. Clinical Pharmacology \& Therapeutics 2008;84:362-369.

34. Chapman BE, Lee S, Kang HP, Chapman WW. Document-Level Classification of CT Pulmonary Angiography Reports based on an Extension of the ConText Algorithm. $J$ Biomed Inform 2011;44:728-737.

35. Chapman B. pyConTextNLP. 2019. at <https://github.com/chapmanbe/pyConTextNLP>.

36. Polubriaginof F, Salmasian H, Albert DA, Vawdrey DK. Challenges with Collecting Smoking Status in Electronic Health Records. AMIA Annu Symp Proc 2018;2017:1392-1400.

37. Cohen J. A Coefficient of Agreement for Nominal Scales. Educational and Psychological Measurement 1960;20:37-46.

38. Denny JC, Ritchie MD, Basford MA, Pulley JM, Bastarache L, Brown-Gentry K, Wang D, Masys DR, Roden DM, Crawford DC. PheWAS: demonstrating the feasibility of a phenomewide scan to discover gene-disease associations. Bioinformatics 2010;26:1205-1210.

39. Wei W-Q, Bastarache LA, Carroll RJ, Marlo JE, Osterman TJ, Gamazon ER, Cox NJ, Roden DM, Denny JC. Evaluating phecodes, clinical classification software, and ICD-9-CM codes for phenome-wide association studies in the electronic health record. PLOS ONE 2017;12:e0175508.

40. Thayer TE, Huang S, Levinson RT, Farber-Eger E, Assad TR, Huston JH, Mosley JD, Wells QS, Brittain EL. Unbiased Phenome-Wide Association Studies of Red Cell Distribution Width Identifies Key Associations with Pulmonary Hypertension. Ann Am Thorac Soc 2019;16:589-598.

41. Hebbring S. Genomic and Phenomic Research in the 21st Century. Trends Genet 2019;35:29-41. 
42. Wolford BN, Willer CJ, Surakka I. Electronic health records: the next wave of complex disease genetics. Hum Mol Genet 2018;27:R14-R21.

43. Roden DM. Phenome-wide association studies: a new method for functional genomics in humans. J Physiol (Lond) 2017;595:4109-4115.

44. Denny JC, Bastarache L, Roden DM. Phenome-Wide Association Studies as a Tool to Advance Precision Medicine. Annual Review of Genomics and Human Genetics 2016;17:353-373.

45. Price AL, Patterson NJ, Plenge RM, Weinblatt ME, Shadick NA, Reich D. Principal components analysis corrects for stratification in genome-wide association studies. Nature Genetics 2006;38:904.

46. Chang CC, Chow CC, Tellier LC, Vattikuti S, Purcell SM, Lee JJ. Second-generation PLINK: rising to the challenge of larger and richer datasets. Gigascience 2015;4:7.

47. Centers for Disease Control and Prevention. Map of Cigarette Use Among Adults | STATE System | CDC. 2019;at <https://www.cdc.gov/statesystem/cigaretteuseadult.html>.

48. Wysocki T, Diaz MCG, Crutchfield JH, Franciosi JP, Werk LN. Electronic health record as a research tool: Frequency of exposure to targeted clinical problems and health care providers' clinical proficiency. J Biomed Inform 2017;70:14-26.

49. Tse J, You W. How accurate is the electronic health record? - a pilot study evaluating information accuracy in a primary care setting. Stud Health Technol Inform 2011;168:158164.

50. Song Y, Skinner J, Bynum J, Sutherland J, Wennberg JE, Fisher ES. Regional Variations in Diagnostic Practices. N Engl J Med 2010;363:45-53.

51. Chan KS, Fowles JB, Weiner JP. Review: electronic health records and the reliability and validity of quality measures: a review of the literature. Med Care Res Rev 2010;67:503-527. 
52. Hersh WR, Weiner MG, Embi PJ, Logan JR, Payne PRO, Bernstam EV, Lehmann HP, Hripcsak G, Hartzog TH, Cimino JJ, Saltz JH. Caveats for the Use of Operational Electronic Health Record Data in Comparative Effectiveness Research. Med Care 2013;51:S30-S37.

53. Hogan WR, Wagner MM. Accuracy of data in computer-based patient records. J Am Med Inform Assoc 1997;4:342-355.

54. Weiskopf NG, Weng C. Methods and dimensions of electronic health record data quality assessment: enabling reuse for clinical research. J Am Med Inform Assoc 2013;20:144151.

55. Hripcsak G, Albers DJ. Next-generation phenotyping of electronic health records. J Am Med Inform Assoc 2013;20:117-121.

56. Wei W-Q, Denny JC. Extracting research-quality phenotypes from electronic health records to support precision medicine. Genome Medicine 2015;7:41.

57. Ranu H, Wilde M, Madden B. Pulmonary Function Tests. Ulster Med J 2011;80:84-90.

58. Wei W-Q, Teixeira PL, Mo H, Cronin RM, Warner JL, Denny JC. Combining billing codes, clinical notes, and medications from electronic health records provides superior phenotyping performance. J Am Med Inform Assoc 2016;23:e20-e27.

59. O'Malley KJ, Cook KF, Price MD, Wildes KR, Hurdle JF, Ashton CM. Measuring diagnoses: ICD code accuracy. Health Serv Res 2005;40:1620-1639.

60. Forey BA, Thornton AJ, Lee PN. Systematic review with meta-analysis of the epidemiological evidence relating smoking to COPD, chronic bronchitis and emphysema. BMC Pulmonary Medicine 2011;11:36. 
Figure 1. Study design for algorithm development and Vanderbilt Synthetic Derivative sample size as of March 2019.

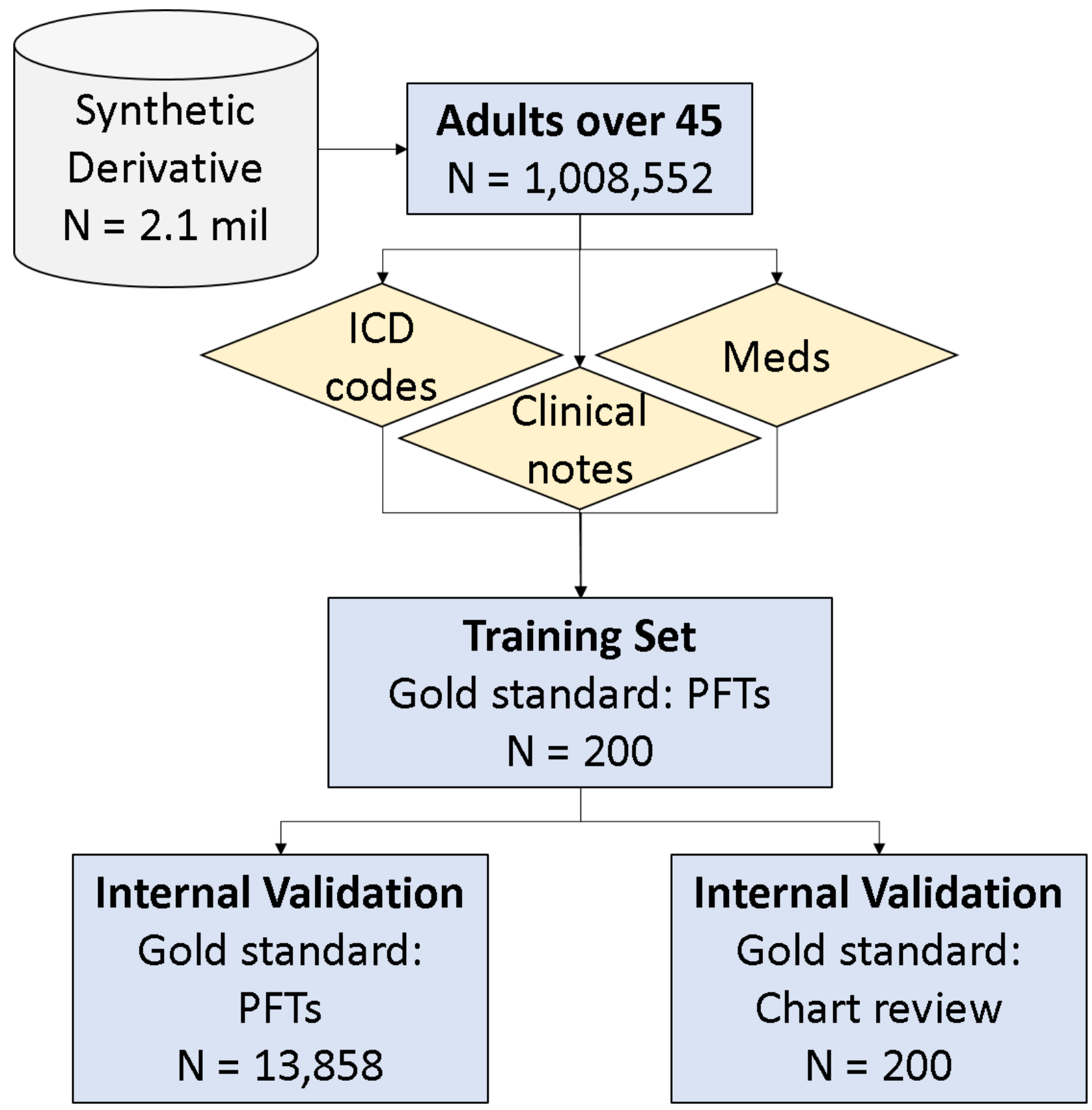

ICD: International Classification of Disease, Meds: medications for chronic obstructive pulmonary disease, PFT: pulmonary function test 
Figure 2. Phenotyping algorithm for chronic obstructive pulmonary disease.

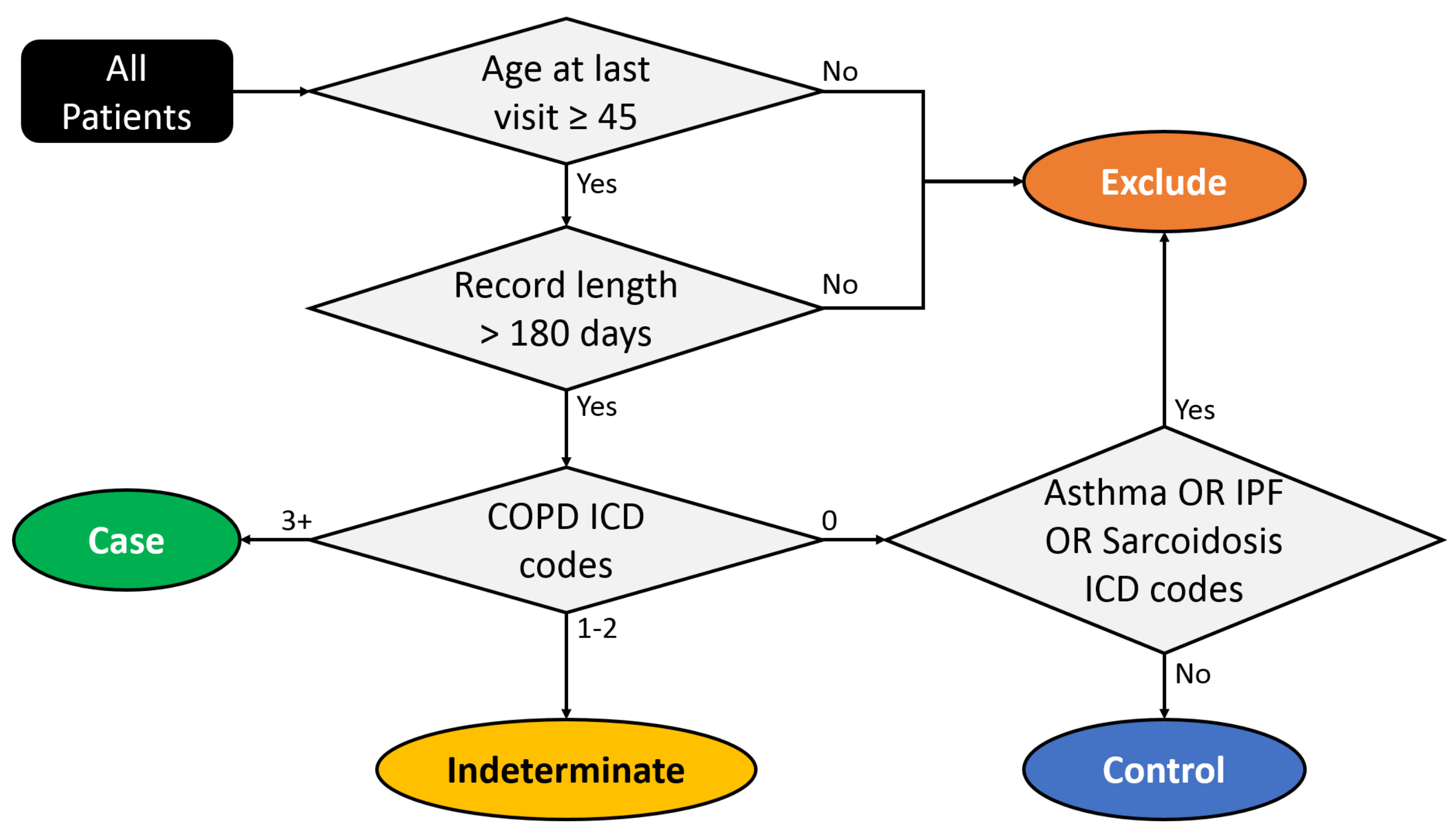

COPD: chronic obstructive pulmonary disease, ICD: International Classification of Disease, IPF: idiopathic pulmonary fibrosis 
Figure 3. Overlap in COPD case definitions among COPD cases over age 45 years in the Synthetic Derivative.

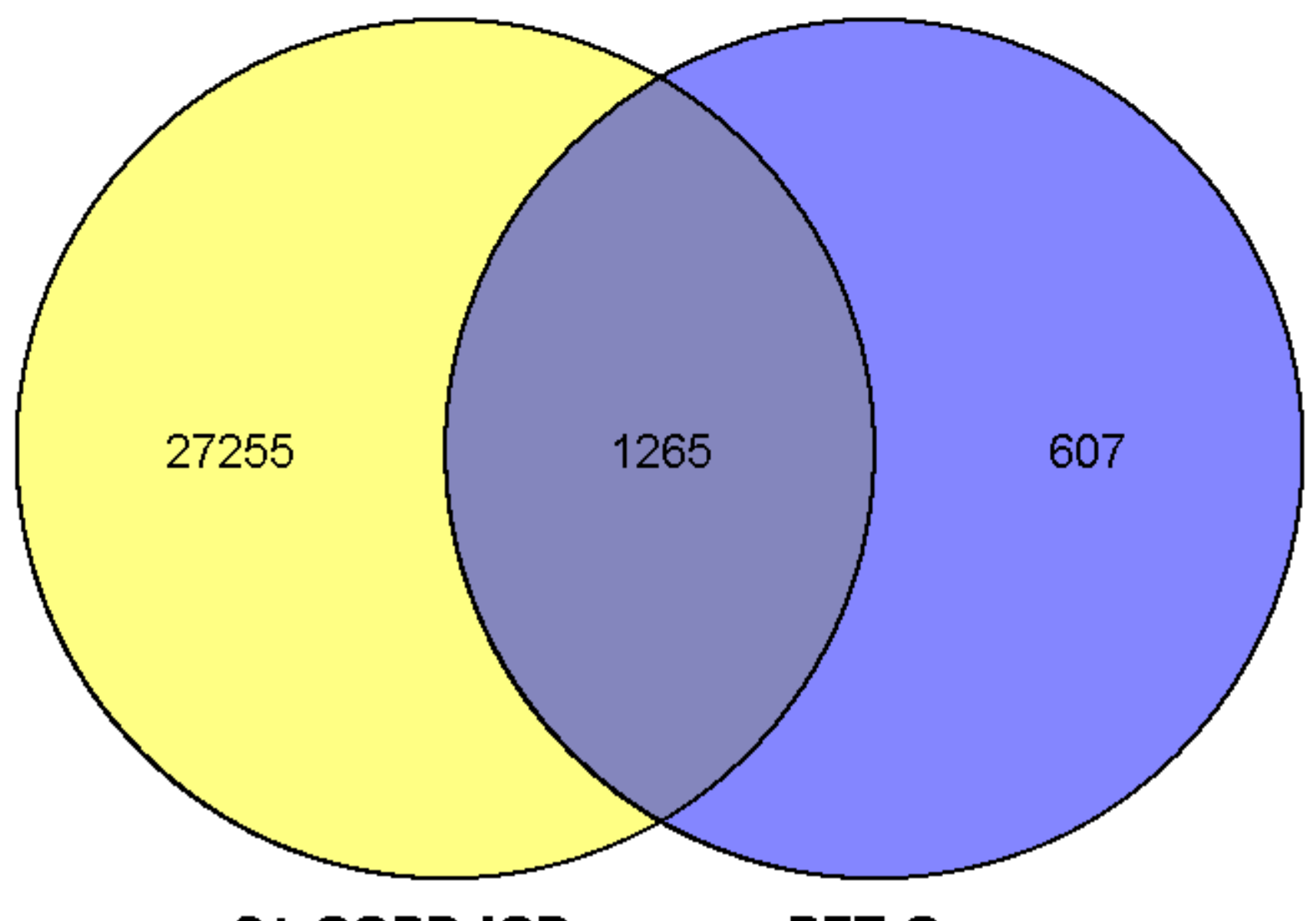

3+ COPD ICD $\quad$ PFT Cases

COPD ICD = International Classification of Disease codes for COPD, PFT cases = pulmonary function test-defined COPD case (postbronchodilator forced expiratory volume in one second/forced vital capacity $<0.7$ ) 
Table 1. Demographic characteristics of development set, internal validation sets, and all adults over age 45 years in the Synthetic Derivative, as of March 2019.

\begin{tabular}{|c|c|c|c|c|}
\hline Variable & $\begin{array}{c}\text { Development Set } \\
N=200\end{array}$ & $\begin{array}{c}\text { Internal Validation } \\
\text { Set (Chart Review) } \\
\quad N=200\end{array}$ & $\begin{array}{c}\text { Internal Validation } \\
\text { Set (PFTs) } \\
N=13,858 \\
\end{array}$ & $\begin{array}{c}\text { SD over age } 45 \\
N=1,008,552\end{array}$ \\
\hline $\begin{array}{l}\text { Median age at last clinic } \\
\text { visit, years (IQR) }\end{array}$ & $\begin{array}{c}65 \\
(58-73)\end{array}$ & $\begin{array}{c}64 \\
(58-74)\end{array}$ & $\begin{array}{c}65 \\
(57-73)\end{array}$ & $\begin{array}{c}61 \\
(53-71)\end{array}$ \\
\hline Female, $\mathrm{N}(\%)$ & $102(51.0)$ & $107(53.5)$ & $7,306(52.7)$ & $545,271(54.1)$ \\
\hline \multicolumn{5}{|l|}{ Race, N (\%) } \\
\hline White & $164(82.0)$ & $156(78.0)$ & $12,010(86.7)$ & $702,679(69.7)$ \\
\hline Black & $28(14.0)$ & $17(8.5)$ & $1,374(9.9)$ & $75,554(7.5)$ \\
\hline Other & $7(3.5)$ & $2(1.0 \%)$ & $180(1.3)$ & $9,007(0.9)$ \\
\hline $\begin{array}{l}\text { Median record length, } \\
\text { years (IQR) }\end{array}$ & $\begin{array}{c}8.6 \\
(4.0-15.4) \\
\end{array}$ & $\begin{array}{c}4.3 \\
(0.9-10.5) \\
\end{array}$ & $\begin{array}{c}8.8 \\
(3.7-15.0) \\
\end{array}$ & $\begin{array}{c}1.9 \\
(0.1-8.2) \\
\end{array}$ \\
\hline Ever smoker, $\mathrm{N}(\%)$ & $113(56.5)$ & $81(40.5)$ & $7,619(55.0)$ & $190,986(18.9)$ \\
\hline \multicolumn{5}{|l|}{ COPD prevalence, $\mathrm{N}(\%)$} \\
\hline Algorithm-based & $66(33.0)$ & $70(35.0)$ & $3,834(27.7)$ & $34,513(3.4)$ \\
\hline PFT-based & $37(18.5)$ & NA & $1,976(14.3)$ & NA \\
\hline
\end{tabular}

SD = synthetic derivative 
Table 2. Clinical validity measures for phenotyping algorithms in development, validation, and PFT sets.

\begin{tabular}{|l|l|c|c|c|c|c|}
\hline Algorithm & Set & Sensitivity (\%) & Specificity (\%) & PPV (\%) & NPV (\%) & F measure \\
\hline 3+ ICD COPD codes & Development & 90.3 & 69.3 & 42.4 & 96.6 & 0.58 \\
\hline & Validation chart & 97.6 & 76.0 & 57.1 & 99.0 & 0.72 \\
\hline & Validation PFT & 84.9 & 68.2 & 33.9 & 95.9 & 0.48 \\
\hline ICD code plus regex & Development & 88.9 & 77.5 & 49.0 & 96.6 & 0.63 \\
\hline & Validation chart & 97.0 & 95.0 & 86.5 & 99.0 & 0.91 \\
\hline & Validation PFT & 80.4 & 79.1 & 39.8 & 95.9 & 0.53 \\
\hline
\end{tabular}

$\mathrm{PFT}=$ pulmonary function test, $\mathrm{PPV}=$ positive predictive value, $\mathrm{NPV}=$ negative predictive value 
Table 3. Demographic and clinical features of COPD cases and controls identified by the 3+ COPD ICD code algorithm, with a minimum floor of 6 months.

\begin{tabular}{|c|c|c|c|}
\hline Characteristic & $\begin{array}{l}\text { COPD Cases } \\
\mathrm{N}=28,520\end{array}$ & $\begin{array}{c}\text { Controls } \\
N=544,056\end{array}$ & $\begin{array}{c}\text { All SD* } \\
\mathrm{N}=623,986\end{array}$ \\
\hline Median age at last visit (IQR) & $\begin{array}{c}69 \\
(60-76) \\
\end{array}$ & $\begin{array}{c}62 \\
(53-71) \\
\end{array}$ & $\begin{array}{c}62 \\
(54-72) \\
\end{array}$ \\
\hline \multicolumn{4}{|l|}{$\operatorname{Sex}(\%)$} \\
\hline Female & $\begin{array}{c}13,356 \\
(46.8)\end{array}$ & $\begin{array}{c}300,402 \\
(55.2)\end{array}$ & $\begin{array}{c}344,179 \\
(55.2)\end{array}$ \\
\hline Male & $\begin{array}{l}15,164 \\
(53.2)\end{array}$ & $\begin{array}{c}243,586 \\
(44.8)\end{array}$ & $\begin{array}{c}279,738 \\
(44.8)\end{array}$ \\
\hline Unknown & $\begin{array}{c}0 \\
(0.0)\end{array}$ & $\begin{array}{c}68 \\
(0.0) \\
\end{array}$ & $\begin{array}{c}69 \\
(0.0) \\
\end{array}$ \\
\hline \multicolumn{4}{|l|}{ Race (\%) } \\
\hline White & $\begin{array}{c}24,795 \\
(86.9)\end{array}$ & $\begin{array}{c}28,349 \\
(78.7)\end{array}$ & $\begin{array}{c}495,961 \\
(79.5)\end{array}$ \\
\hline Black & $\begin{array}{c}2,684 \\
(9.4)\end{array}$ & $\begin{array}{c}45,994 \\
(8.5)\end{array}$ & $\begin{array}{c}54,547 \\
(8.7) \\
\end{array}$ \\
\hline Other & $\begin{array}{l}119 \\
(0.4)\end{array}$ & $\begin{array}{c}6,350 \\
(1.2)\end{array}$ & $\begin{array}{c}6,908 \\
(1.1)\end{array}$ \\
\hline Unknown & $\begin{array}{l}922 \\
(3.2) \\
\end{array}$ & $\begin{array}{l}63,363 \\
(11.6)\end{array}$ & $\begin{array}{l}66,570 \\
(10.7) \\
\end{array}$ \\
\hline \multicolumn{4}{|l|}{ Smoking status } \\
\hline Ever & $\begin{array}{l}15,645 \\
(54.9)\end{array}$ & $\begin{array}{c}124,295 \\
(22.8)\end{array}$ & $\begin{array}{c}157,178 \\
(25.2)\end{array}$ \\
\hline Never & $\begin{array}{l}2,900 \\
(10.2)\end{array}$ & $\begin{array}{c}213,609 \\
(39.3)\end{array}$ & $\begin{array}{c}234,382 \\
(37.6)\end{array}$ \\
\hline Missing & $\begin{array}{l}9,975 \\
(35.0) \\
\end{array}$ & $\begin{array}{c}206,152 \\
(37.9)\end{array}$ & $\begin{array}{c}229,249 \\
(42.7)\end{array}$ \\
\hline $\begin{array}{l}\text { Median record length (years) } \\
\text { (IQR) }\end{array}$ & $\begin{array}{c}7.3 \\
(3.2-13.0)\end{array}$ & $\begin{array}{c}6.2 \\
(2.4-11.5)\end{array}$ & $\begin{array}{c}6.4 \\
(2.5-11.7)\end{array}$ \\
\hline $\begin{array}{l}\text { Number of respiratory meds } \\
\text { (median, IQR) }\end{array}$ & $\begin{array}{c}107 \\
(32-277)\end{array}$ & $\begin{array}{c}16 \\
(5-54)\end{array}$ & $\begin{array}{c}19 \\
(6-67)\end{array}$ \\
\hline $\begin{array}{l}\text { Top } 5 \text { phecodes by frequency } \\
(\%)\end{array}$ & & 1 & \\
\hline 1 & $\begin{array}{l}\text { Chronic airway obstruction } \\
\text { (100) }\end{array}$ & $\begin{array}{l}\text { Hypertension } \\
(37.0)\end{array}$ & $\begin{array}{l}\text { Hypertension } \\
(40.9)\end{array}$ \\
\hline
\end{tabular}




\begin{tabular}{|c|c|c|c|}
\hline 2 & $\begin{array}{c}\text { Hypertension } \\
(77.1)\end{array}$ & $\begin{array}{c}\text { Essential hypertension } \\
(36.2)\end{array}$ & $\begin{array}{c}\text { Essential hypertension } \\
(40.1)\end{array}$ \\
\hline 3 & $\begin{array}{c}\text { Other symptoms of respiratory } \\
\text { system (75.4) }\end{array}$ & $\begin{array}{c}\text { Disorders of lipoid } \\
\text { metabolism (26.1) }\end{array}$ & $\begin{array}{c}\text { Other symptoms of respiratory } \\
\text { system (29.3) }\end{array}$ \\
\hline 4 & $\begin{array}{c}\text { Essential hypertension } \\
(75.4)\end{array}$ & $\begin{array}{c}\text { Hyperlipidemia } \\
(26.0)\end{array}$ & $\begin{array}{c}\text { Disorders of lipoid metabolism } \\
(28.7)\end{array}$ \\
\hline 5 & Tobacco use disorder \\
$(63.0)$ & $\begin{array}{c}\text { Other symptoms of } \\
\text { respiratory system (24.1) }\end{array}$ & $\begin{array}{c}\text { Hyperlipidemia } \\
(28.7)\end{array}$ \\
\hline
\end{tabular}

*Individuals with record lengths longer than 180 days.

${ }^{* *}$ Number of respiratory medications includes only mentions of medications on distinct days. 